\title{
SLEEP DISTURBANCE AND RAGE ATTACKS IN OPSOCLONUS-MYOCLONUS SYNDROME: RESPONSE TO TRAZODONE
}

\author{
Michael R. Pranzatelli, MD, Elizabeth D. Tate, C-Fnp, mn, William S. Dukart, MD, Mary jo Flint, MD, \\ Michael T. Hoffman, MD, and Amy E. Oksa, MD
}

Objectives Parents of ehildren with opsoclonus-myoclonus syndrome (OMS) frequently describe poor sleep and rage attacks. We hypothesized that these manifestations are related and could result from underlying monoaminergic dysfunction.

Study design We clinically characterized the sleep and behavioral characteristics of 51 young children with OMS; 19 of those with the most disruptive sleep patterns were treated with trazodone, a soporific serotonergic agent.

Results Sleep disturbances, including prolonged sleep latency, fragmented sleep, reduced quantity of sleep, snoring, and nonrestorative sleep, were reported in 32 children, and frequent rage attacks were reported in 25 . In $\mathbf{5 9 \%}$ of the poor sleepers, parents felt that the problem was severe enough to warrant treatment. Children sleeping $<10$ hours/night had a higher rage frequency than those who slept more. Of the children who required trazodone, $84 \%$ were receiving corticosteroids or adrenocorticotropic hormone (corticotrophin), compared with $37 \%$ in the subgroup with normal sleep. Trazodone (3.0 \pm 0.4 $\mathrm{mg} / \mathrm{kg} /$ day) improved sleep and behavior in $95 \%$ of the children, significantly increasing total sleep time by $72 \%$, decreasing the number of awakenings by $76 \%$, and reducing rage attacks by $33 \%$.

Conclusions Children with OMS exhibited multiple types of sleep disturbances, which contributed to rage attacks. Trazodone was effective in improving sleep and decreasing rage attacks and was well tolerated, even in toddlers. $(J$ Pediatr 2005;147:372-8)

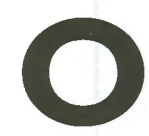

psoclonus-myoclonus syndrome (OMS) is a neuroblastoma-associated paraneoplastic disorder with serious neuropsychiatric sequelae. Of all of the behavioral symptoms of OMS, such as cognitive impairment, attention deficit disorder (ADD), and obsessive-compulsive disorder, sleep disturbance and rage attacks are the most difficult for the family to cope with. ${ }^{1}$ Reduced quality of sleep can also harm the developing child by impairing emotional development, learning, and growth. ${ }^{2}$ Multiple pharmacologic interventions have been unsuccessful in children with OMS, because of a lack of efficacy or the propensity for paradoxical reactions to sedatives in this disorder. ${ }^{3}$

Trazodone hydrochloride, a sedating triazolopyridine derivative with some anxiolytic and hypnotic properties, was first marketed in the United States as an antidepressant in 1983. It is principally a serotonergic agent. ${ }^{4}$ In adults, the antidepressant effect occurs at doses of 300 to $600 \mathrm{mg}$, but in sub-antidepressant doses (50 to $100 \mathrm{mg}$ ), it also treats depression-associated sleep disorders. ${ }^{5}$ Although understudied in children under 12 years old, it is used in older children to treat migraine headaches, ${ }^{6}$ disruptive behavior, ${ }^{7}$ depression, ${ }^{8}$ and sleep disorders. ${ }^{9}$

We hypothesized a perturbation of monoaminergic neurotransmission to account for sleep disturbances and rage attacks in OMS. Abnormalities of cerebrospinal fluid (CSF) monoamine metabolites have been found in $\mathrm{OMS}^{10}$ and in disruptive behavioral disorders of children and adolescents. ${ }^{11}$ Trazodone, with its serotonergic properties and good safety index, seemed like an ideal drug for sleeping problems in this population, and after seeing

\begin{tabular}{llll}
\hline ACTH & Adrenocorticotropic hormone (corticotropin) & 5-HT & 5-hydroxytryptamine \\
ADD & Attention deficit disorder & HVA & Homovanillic acid \\
ADHD & Attention deficit hyperactivity disorder & m-CPP & m-chlorophenylpiperazine \\
CSF & Cerebrospinal fluid & OMS & Opsodonus-myoclonus syndrome \\
5-HIAA & 5-hydroxyindoleacetic acid & REM & Rapid eye movement \\
\hline
\end{tabular}

From the Departments of Neurology
and Pediatrics, Southern Illinois Uni-
versity School of Medicine, Springfield,
Illinois; Greenbriar Physicians, Inc.,
Ronceverte, West Virginia; Pediatric
Professional Association, Overland
Park, Kansas; Elmhurst Clinic Pediat-
rics, Elmhurst, Illinois; and Dickinson
Clinic, MedCenter One Health Sys-
tems, Dickinson, North Dakota.
Supported by funds from the Chil-
dren's Miracle Network.
Submitted for publication Jan 4, 2005;
last revision received Apr 6, 2005;
accepted May 6, 2005 .
Reprint requests: Dr. Michael R.
Pranzatelli, National Pediatric Myoclo-
nus Center, SIU School of Medicine,
PO Box 19643, Springfield, UL 62794-
9643 . E-mail: mpranzatelli@siumed.
edu.
$0022-3476 / \$$ - see front matter
Copyright (C) 2005 Elsevier Inc. All rights
reserved.
I0.1016/j.jpeds.2005.05.016 
healthy children and adolescents: a multicenter trial including 1141 subjects. J Pediatr 1997;130:178-84.

15. Lurbe E, Sorof JM, Daniels SR. Clinical and research aspects of ambulatory blood pressure monitoring in children. J Pediatr 2004;144:7-16. 16. Staessen JA, Bieniaszewski L, O’Brien E, Gosse P, Hayashi H, Imai Y, et al. Nocturnal blood pressure fall on ambulatory monitoring in large international database. Hypertension 1999;29:30-9.

17. Hogg RJ, Furth S, Lemley KV, Portman R, Schwartz GJ, Coresh J, et al. National kidney foundation's kidney disease outcomes quality initiative clinical practice guidelines for chronic kidney disease in children and adolescents: evaluation, classification, and stratification. Pediatrics 2003;111: 1416-21.

18. Flynn JT. Impact of ambulatory blood pressure monitoring on the management of hypertension in children. Blood Press Monit 2000;5:211-6. 19. Sorof JM, Poffenbarger T, Franco K, Portman R. Evaluation of white coat hypertension in children: importance of the definitions of normal ambulatory blood pressure and the severity of casual hypertension. Am J Hypertens 2001;14:855-60.

20. Patzer L, Seeman T, Luck C, Wühl E, Janda J, Misselwitz J. Day- and night-time blood pressure elevation in children with higher grades of renal scarring. J Pediatr 2003;142:117-22.

21. Bartosh SM, Aronson AJ. Childhood hypertension: an update on etiology, diagnosis and treatment. Pediatr Clin North Am 1999;46:235-52.

22. Feld LG, Springate JE, Waz WR. Special topics in pediatric hypertension. Semin Nephrol 1998;18:295-303.

23. He $\mathrm{Q}_{2}$ Ding ZY, Fong DY, Karlberg J. Blood pressure is associated with body mass index in both normal and obese children. Hypertension 2000;36: 165-70.
24. Sorof JM, Lai D, Turner J, Poffenbarger T, Portman RJ. Overweight, ethnicity, and the prevalence of hypertension in school-aged children. Pediatrics 2004;113:475-82.

25. Covic A, Goldsmith D. Ambulatory blood pressure monitoring: an essential tool for blood pressure assessment in uraemic patients. Nephrol Dial Transplant 2002;17:1737-41.

26. Farmer CK, Goldsmith DJ, Quinn JD, Dallyn P, Cox J, Kingswood JC, et al. Progression of diabetic nephropathy: is diurnal blood pressure rhythm as important as absolute blood pressure level? Nephrol Dial Transplant 1998;13: $635-9$.

27. Mitsnefes M, Kimball TR, Daniels SR. Office and ambulatory blood pressure elevation in children with chronic renal failure. Pediatr Nephrol 2003; $18: 145-9$

28. Lingens N, Soergel M, Loirat C, Busch C, Lemmer B, Scharer K. Ambulatory blood pressure monitoring in paediatric patients treated by regular haemodialysis and peritoneal dialysis. Pediatr Nephrol 1995;9: $167-72$.

29. Lingens N, Dobos E, Witte K, Busch C, Lemmer B, Klaus G, et al. Twenty-four-hour ambulatory blood pressure profiles in pediatric patients after renal transplantation. Pediatr Nephrol 1997;11:23-6.

30. Lurbe E, Aguilar F, Gomez A, Tacons J, Alvarez V, Redon J. Reproducibility of ambulatory blood pressure monitoring in children. J Hypertens 1993;11(Supp1 5):S288-9.

31. Mochizuki $Y$, Okutani M, Donfeng $Y$, Iwasaki $H$, Takusagawa M, Kohno I, et al. Limited reproducibility of circadian variation in blood pressure dippers and nondippers. Am J Hypertens 1998;11:403-9.

32. Stolarz K, Staessen JA, O'Brien ET. Night-time blood pressure: dipping. into the future. J Hypertens 2002;20:2131-3.

Access to The Journal of Pediatrics Online is now reserved for print subscribers!

Full-text access to The Journal of Pediatrics Online is available for all print subscribers. To activate your individual online subscription, please visit The Journal of Pediatrics Online, point your browser to http://www.us.elsevierhealth.com/jpeds, follow the prompts to activate online access here, and follow the instructions. To activate your account, you will need your subscriber account number, which you can find on your mailing label (note: the number of digits in your subscriber account number varies from 6 to 10). See the example below in which the subscriber account number has been circled:

\section{Sample mailing label}

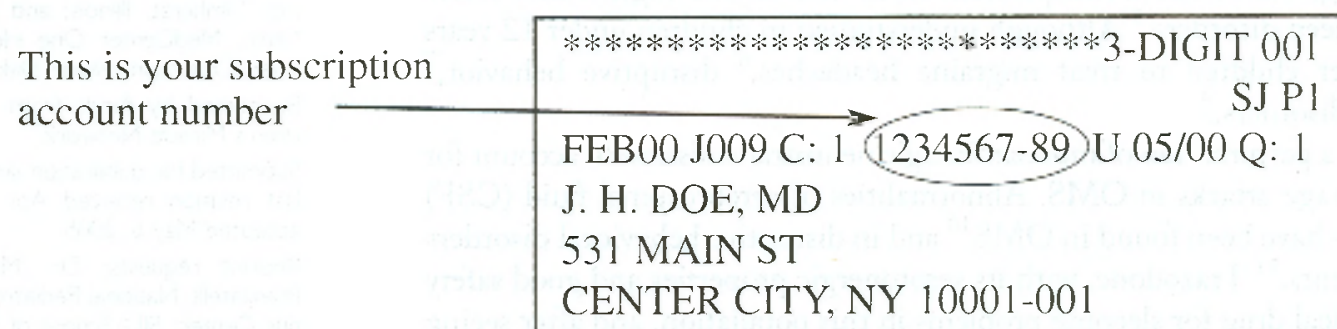

Personal subscriptions to The Journal of Pediatrics Online are for individual use only and may not be transferred. Use of The Journal of Pediatrics Online is subject to agreement to the terms and conditions as indicated online. 
Table I. Characteristics of subjects with sleep problems and response to trazodone

\begin{tabular}{|c|c|c|c|c|c|}
\hline \multirow[b]{2}{*}{ Characteristic } & \multirow{2}{*}{$\begin{array}{c}\text { All OMS } \\
(\text { from } n=51) \\
\%\end{array}$} & \multicolumn{2}{|c|}{$\begin{array}{l}\text { Sleep problems } \\
\text { (from } n=51 \text { ) }\end{array}$} & \multicolumn{2}{|c|}{$\begin{array}{l}\text { Response to trazodone } \\
\quad(\text { from } n=19 \text { ) }\end{array}$} \\
\hline & & Yes \% & No \% & Yes \% (n) & No \% (n) \\
\hline \multicolumn{6}{|l|}{ Age category } \\
\hline Toddlers & 43 & 33 & 10 & $37(7)$ & $5(1)$ \\
\hline Preschool & 33 & 20 & 14 & $42(8)$ & 0 \\
\hline \multicolumn{6}{|l|}{ Gender } \\
\hline Boys & 43 & 25 & 18 & $42(8)$ & 0 \\
\hline Girls & 57 & 39 & 18 & $53(10)$ & $5(1)$ \\
\hline \multicolumn{6}{|l|}{ Etiology } \\
\hline No tumor found & 59 & 31 & 26 & $53(10)$ & $5(1)$ \\
\hline Tumor found & 41 & 33 & 10 & $42(8)$ & 0 \\
\hline \multicolumn{6}{|c|}{ Attention problems/hyperactivity } \\
\hline No & 45 & 27 & 18 & $37(7)$ & 0 \\
\hline Yes & 55 & 35 & 20 & $58(11)$ & $5(1)$ \\
\hline \multicolumn{6}{|l|}{ Current steroids or $\mathrm{ACTH}$} \\
\hline No & 41 & 22 & 23 & $16(3)$ & 0 \\
\hline Yes & 59 & 41 & 14 & $79(15)$ & $5(1)$ \\
\hline \multicolumn{6}{|c|}{ OMS motor severity category } \\
\hline Mild & 61 & 39 & 22 & $79(15)$ & 0 \\
\hline Moderate & 25 & 14 & 12 & $5(I)$ & 0 \\
\hline Severe & 14 & 12 & 1 & II (2) & $5(1)$ \\
\hline
\end{tabular}

"Problems sleeping" refers to $>2$ types of sleep disturbances. "Response to trazodone" indicates a "yes" response from parents to the question of whether trazodone improved their child's sleep. Age category was defined as infant $=<1.5$ years; toddler $=1.5$ to $<3$ years; preschool $=3$ to $<5$ years; school age $=\geq 5$ years. Rage attacks were designated as infrequent if $<3 /$ week. OMS severity category was based on total score as follows: mild $=0$ to 12 ; moderate $=13$ to 24 ; severe $=25$ to 36. OMS duration category was defined as follows: acute $=<3$ months; subacute $=3$ to 12 months; chronic $=>12$ months. Clinical characteristics had no statistically significant effects on problems sleeping or response to trazodone, except for current steroids or ACTH $(P=.0015$; Fisher's exact test).

its benefit, we adopted it into our practice. We now report on the sleep and behavioral characteristics of children with OMS and a retrospective series on the response to trazodone as symptomatic therapy. Because many were being treated with corticosteroids or corticotropin (ACTH), which can modify sleep $^{12}$ and CSF monoamines, ${ }^{13}$ anti-inflammatory therapy was identified as an important variable.

\section{METHODS}

\section{Subjects}

Fifty-one children with OMS, who were recruited from 2001 to 2004 through the National Pediatric Myoclonus Center and its website (www.omsusa.org) or physician referrals, underwent comprehensive clinical data collection and neurologic evaluation under an Institutional Review Board- approved protocol. Informed consent was obtained from the parents. Each child had been evaluated previously for occult neuroblastoma, and those with a tumor had undergone surgical resection. The clinical characteristics of the study population are presented in Table I. Mean age \pm standard error of the mean for the entire cohort was $4.3 \pm 0.5$ years (range, 1.7 to 17 years).

\section{Subjective Sleep Assessment}

Parents had been interviewed as to whether their child regularly had trouble falling asleep (insomnia), could not sleep through the night (fragmented sleep), had fitful or restless sleep, habitual snoring, sleeptalking (somniloquy), or sleepwalking (somnambulism), or woke up tired and cranky (poor awakening quality, nonrestorative sleep). They were asked about the total number of hours that the child usually slept each 

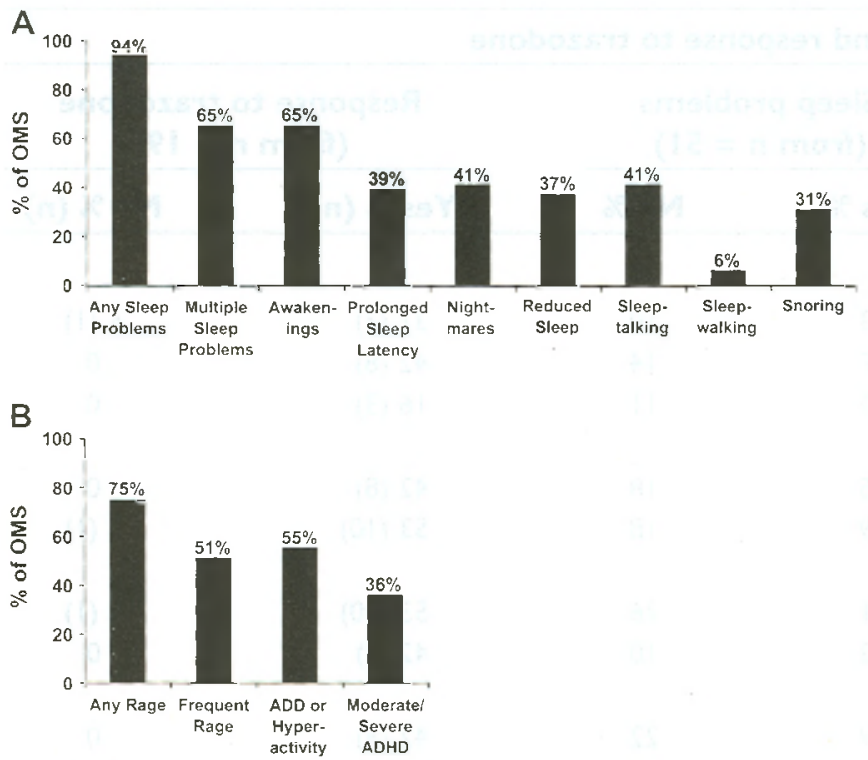

Figure I. Percentages of various types of sleep problems (A) or rage and other behaviors (B) in 51 children with OMS. (A) "Multiple sleep problems" was defined as more than 2 types of problems sleeping. "Reduced sleep" was defined as $<10$ hours/night. All other designations are the result of yes/no answers. (B) "Frequent rage" was defined as rage score $\geq 3$. "ADD or hyperactivity" refers to symptoms of $\mathrm{ADD} / \mathrm{ADHD}$ described to parents, who were then asked to rate them. Children with moderate or severe symptoms are represented by "moderate/severe ADHD."

night and the number of nightly awakenings. Prolonged sleep latency was defined as taking more than 30 minutes to fall asleep, parents were well aware of it because they had to lie down with, hold, or otherwise console the child until sleep onset. Many of the children slept with their parents or went to their parents' bed during the night when they woke up, so the parents had no problem providing the other information either.

\section{Behavioral Assessment}

Parents were questioned about rage attacks, which were described to them as extremely exaggerated temper tantrums. Rage was semiquantitated on a Likert scale from 0 to 5 as follows: $0=$ none, $1=1$ to 2 episodes $/$ week, $2=3$ episodes $/$ week, 3 = 1 episode/day, $4=2$ episodes $/$ day, $5=$ multiple episodes/day. Parents were also asked about aggressive behavior (eg, biting, kicking, hair pulling, shoving) and symptoms of ADD (eg, hyperactivity, distractability, poor attention span). ${ }^{14}$

\section{OMS Severity Assessment}

The children were videotaped using a standardized format. A trained observer scored the videotapes using the OMS Evaluation Scale, a 12 -item scale for assessing motor impairment. ${ }^{15}$ Each item was rated from 0 to 3 , and subscores were tallied into a total score, which was used for subsequent comparisons.

\section{Drug Administration}

When parents had requested medication for their child's sleep disturbance, trazodone had been started as a single oral dose 1 hour before the desired bedtime. Toddlers were startec on $25 \mathrm{mg}$, and the parents were instructed to increase the dost by $25 \mathrm{mg}$ at 2-week intervals up to $100 \mathrm{mg}$ if necessary tc improve sleep and control of rage. For older children, the starting dose was $50 \mathrm{mg}$, with titration up to $150 \mathrm{mg}$ as needed. Most parents were willing to increase the dose to achieve the desired effect, but some could not be persuaded to go above the starting dose.

\section{Data Analysis}

Statistical analysis was performed using Microsoft Excel and the Statistical Analysis System (SAS) as follows: comparisons of number of subjects by Fisher's exact test or the $\chi^{2}$ test, group means by 2 -tailed $t$-tests or analysis of variance, trends in frequency by the Cochran-Armitage trend test, posttreatment changes in the percentage of subjects with sleep or behavioral problems by McNemar's test, and posttreatment changes in means by paired $t$-tests. The level of significance was set at $P<.05$. Primary independent variables were key sleep characteristics (prolonged latency of sleep onset, number of nocturnal awakenings, sleep duration), behavior (rage and attention deficit symptoms), and ACTH or steroid treatment. Sleep duration, predetermined to be the most fundamental sleep variable, was used to divide the dataset into 3 groups based on reduced sleep time. A cutoff of 10 hours of sleep per night was chosen, based on a conservative estimate of the number of hours of sleep a child needs at age 4 years, ${ }^{3}$ the mean age of the children in our study.

\section{RESULTS}

\section{Characterization of Sleep Disturbances}

More than $90 \%$ of parents reported that their child had some difficulty sleeping, and $65 \%$ reported more than 2 sleep problems (Figure 1A). The percentage of affected children was highest for awakenings during the night $(65 \%)$ and was otherwise similar for prolonged sleep latency, reduced sleep, nightmares, sleeptalking, and snoring ( $31 \%$ to $41 \%)$. Sleepwalking occurred infrequently.

In the prodromal phase of the illness, before opsoclonus or myoclonus, children exhibited extreme irritability, accompanied by sleeplessness or 15 -minute sleep intervals. Some demanded to be held almost constantly. The parents reported feeling stressed and sleep-deprived.

Previously, several different drugs, including clonazepam, codeine, diazepam, diphenhydramine, lorazepam, and melatonin, had been tried unsuccessfully for sleep. Parents recalled that during the acute phase of OMS, intravenous morphine, fentanyl, or midazolam had been given in the hospital, with paradoxical reactions or lack of efficacy.

\section{Characterization of Rage}

Rage attacks were reported in $75 \%$ of the children (Figure 1B), with frequent attacks (at least 1 rage episode per day, or a rage score of $\geq 3$ ) in as many as $49 \%$. This percentage 
Table II. Effect of sleep duration on other sleep variables and behaviors

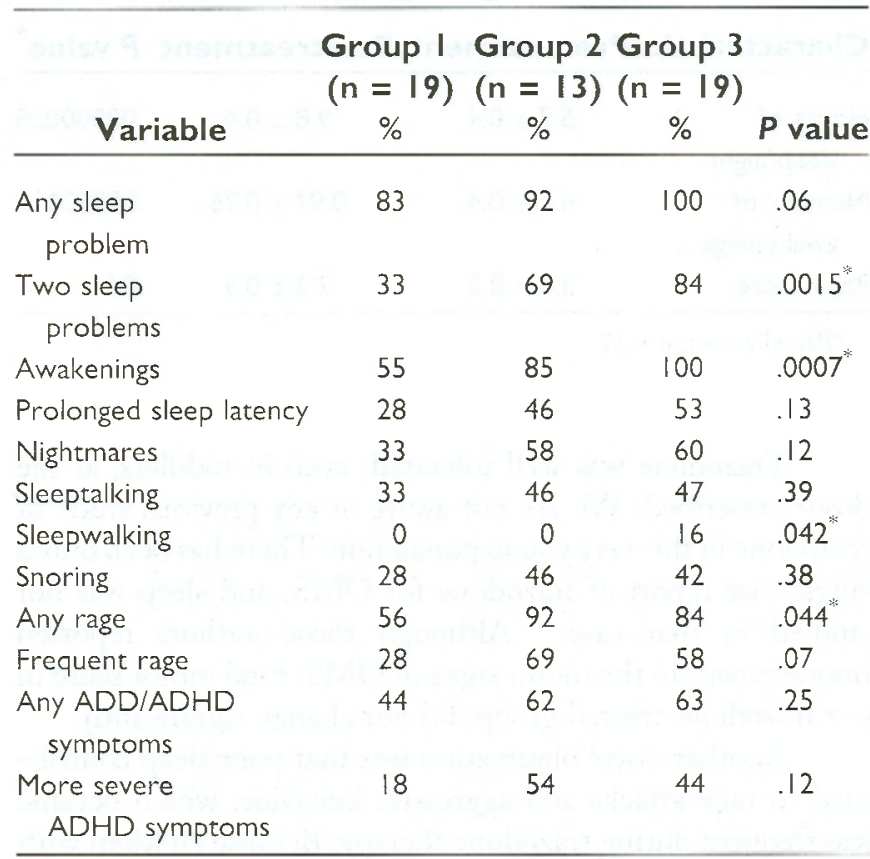

Ordered severity groupings were created by whether children slept $\geq 10$ hours (normal sleep time; group 1), $<10$ hours without parents requesting sleep medication (reduced sleep time; group 2), and $<10$ hours with parents asking for sleep medication (reduced sleep time; group 3). Children with reduced sleep had multiple other sleep problems.

*Statistically significant trend across groups; Cochran-Armitage trend test.

was comparable to that for parent-reported symptoms of attention deficit hyperactivity disorder (ADHD).

Parents volunteered such terms as "meltdowns," even "nuclear meltdowns," to describe the episodes. These occurred as attacks of screaming, often brought on by the child not getting his or her way, but at other times with frustration or for no apparent reason. Attack duration was 20 minutes to several hours. During the episodes, the children were unconsolable. Aggression was directed toward other family members, often a specific parent. Parents and grandparents showed bruises or scars where they had been bitten. Children often bit themselves on the arms or banged their heads on the floor or wall during the attacks. Parents had no difficulty distinguishing these rage attacks from normal tantrums, which they thought of as being orders of magnitude less severe. After a rage attack, many children were remorseful, and the transition back to normal mood was "as if a switch had been thrown." Multiple episodes in a day were not uncommon.

Rage attacks sometimes occurred in the clinic. Characteristics of these attacks included trivial provocations, sudden changes in mood, ear-piercing screaming, loss of selfcontrol, and "shutting down." Some children crawled under an office chair, getting close to the wall or corner, and engaged in head banging or hiding their faces while crying. Others kicked, hurled objects, threw back their heads, and slammed doors. One slapped his mother across the face and yanked her hair during the peak of crying.
Table III. Relation of reduced sleep to rage frequency

\begin{tabular}{ccccc}
\hline Group & N & Age (years) & Rage score & P values \\
\hline 1 & 18 & $4.3 \pm 0.7$ & $1.7 \pm 0.5$ & - \\
2 & 13 & $4.7 \pm 1.0$ & $3.4 \pm 0.5$ & $.038^{*}$ \\
3 & 19 & $4.1 \pm 0.8$ & $3.2 \pm 0.5$ & $.015^{*}$ \\
\hline
\end{tabular}

Rage was scored on a scale from 0 to 5, with 3 representing 1 episode/day. There was a statistically significant main effect of group on rage frequency $(F=3.5 ; P=.038$; analysis of variance).

${ }^{*}$ Rage score (an index of rage frequency/severity) was increased significantly in groups 2 and 3 , compared to group 1 (2-tailed $t$ test).

\section{Relation of Clinical Variables}

The only clinical or demographic variable that significantly affected sleep disturbance was current steroid or ACTH use (Table I). When OMS was classified on the basis of total sleep time ( $\geq 10$ hours, normal sleep; $<10$ hours, reduced sleep), 3 groups were created: normal sleep duration (group 1), reduced sleep duration for which parents did not seek treatment (group 2), and reduced sleep duration for which parents sought treatment (group 3). Steroids or ACTH were currently used in $37 \%$ of group 1 children, $54 \%$ of group 2 children, and $84 \%$ of group 3 children. The proportion of the combined steroid and ACTH-treated children increased with increasing sleep disurbances $\left(P=.01 ; \chi^{2}\right.$ test). Although the proportion of steroid-treated children remained unchanged, that of ACTH-treated children increased $(P=.001)$. This represented a significant trend across the groups. In group 3 , when ACTH dose was divided at the median into "low-dose" $\left(<10 \mathrm{U} / \mathrm{m}^{2} /\right.$ day $)$ and "high dose" $\left(\geq 10 \mathrm{U} / \mathrm{m}^{2} /\right.$ day $)$, the number of hours of sleep was lower in the high-dose group $(4.8 \pm 0.5)$ than in the low-dose group $(7.1 \pm 0.8)(P=.028$; 2-tailed $t$-test).

Statistically significant trends were found across the 3 groups (Table II). Children with reduced sleep also had multiple other sleep problems and more nighttime awakenings, sleepwalking, and rage. Although total motor score and OMS duration did not differ significantly between groups, rage score was significantly higher in groups 2 and 3 than in group 1 (Table III). The rage score was higher in children with symptoms of ADD (3.2 \pm 0.4$)$ than in those without such symptoms $(2.0 \pm 0.4)(P=.044 ; 2$-tailed $t$-test $)$. When group 3 was divided into infrequent rage (score $<3$ ) and frequent rage $(\geq 3)$, sleep latency was longer in those with frequent rage $(41.7 \pm 8.8 \mathrm{~min})$ than in those with infrequent rage $(17.9 \pm 5.1$ min) $(P=.049 ; 2$-tailed $t$-test $)$.

Children in group 3 were more likely to have received multiple immunotherapies in the past than those in group $1(P=.007 ; 2$-tailed $t$-test $)$. The same was true of immunotherapy during trazodone treatment $(P=.002 ; t$-test $)$. In group 3,8 of 10 children with $\geq 4$ awakenings/night had tumors, compared with 0 of 7 with $<4$ awakenings ( $P=.002$; Fisher's exact test).

When group 3 was divided into snoring and nonsnoring subgroups, there were no statistically significant differences in 


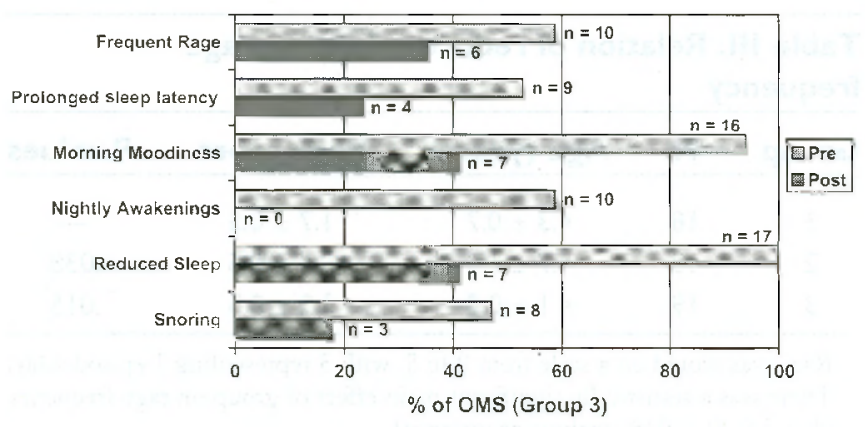

Figure 2. Histogram of the effect of trazodone on the percentage of children with sleep problems, rage, and other behaviors in OMS. "Reduced sleep" was defined as $<10$ hours/night. "Awakenings" was defined as $\geq 4 /$ night. "Prolonged sleep latency" denotes sleep latency $>30$ minutes. Trazodone significantly reduced morning moodiness $(P=.0027)$ and snoring $(P=.025)$, according to McNemar's test. Variance was lacking for posttreatment nightly awakenings $(0 \%)$ and pretreatment reduced sleep (100\%), so no statistical test could be used, but the response to treatment was dramatic.

number of night awakenings, rage scores, or percent with ADD/ADHD symptoms. Snoring was not significantly more frequent in those on high-dose ACTH than in those on lowdose ACTH.

\section{Response to Trazodone}

Treatment with trazodone significantly reduced the number of children with sleep problems (Figure 2). Trazodone also improved quantitative features of sleep and rage (Table IV). The mean dose was $3.0 \pm 0.4 \mathrm{mg} / \mathrm{kg} /$ day (range, 1.2 to 6.9 $\mathrm{mg} / \mathrm{kg} /$ day; median, $2.6 \mathrm{mg} / \mathrm{kg} /$ day). The mean duration of trazodone therapy was $1.1 \pm 0.2$ years (range, 0.08 to 2.4 years; median, 1.0 year).

The effects of trazodone on sleep were not dosedependent, and trazodone dose did not correlate with the ACTH dose. To further assess the effect of trazodone dose, the children were divided into low-dose $(\mathrm{n}=8)$ and high-dose $(\mathrm{n}=9)$ groups at the median dose of $2.6 \mathrm{mg} / \mathrm{kg}$. The highdose subgroup contained significantly more girls $(P=.03)$, younger children $(P=.01)$, and more severe motor symptoms $(P=.04)$ (data not shown), preventing further analysis.

\section{DISCUSSION}

This study demonstrates the prevalence of sleep disturbance in children with OMS and these children's responsiveness to trazodone. The $94 \%$ of children with OMS who had difficulty sleeping exceeds the estimated $24 \%$ to $43 \%$ of children with sleep problems in the general population. ${ }^{16}$ Poor sleep quality, caused by sleep fragmentation or sleep deprivation, ${ }^{17}$ may increase irritability and behavior problems, and tired children tend to become hyperactive. ${ }^{2}$ Restricting sleep by as little as 1 hour in young children has been associated with significant neurobehavioral decline. ${ }^{18}$ The abnormalities in sleep initiation and maintenance in these children with OMS were similar to those reported for depression. ${ }^{19}$
Table IV. Effect of trazodone on quantitative features of sleep and rage in group 3

\begin{tabular}{lccc}
\hline Characteristic Pretreatment Posttreatment & $P$ value \\
\hline $\begin{array}{c}\text { Hours of } \\
\text { sleep/night }\end{array}$ & $5.7 \pm 0.4$ & $9.8 \pm 0.4$ & .00000025 \\
$\begin{array}{c}\text { Number of } \\
\text { awakenings }\end{array}$ & $4.1 \pm 0.4$ & $0.97 \pm 0.26$ & .00000016 \\
Rage score & $3.3 \pm 0.5$ & $2.2 \pm 0.5$ & .04 \\
\hline
\end{tabular}

*Paired $t$ - test, $\mathrm{n}=17$.

Trazodone was well tolerated, even in toddlers, at the doses prescribed. We are not aware of any previous study of trazodone in this very young population. There has been only a single case report of trazodone for OMS, and sleep was not studied in that case. ${ }^{20}$ Although those authors reported improvement in the motor signs of OMS, total motor score in our trazodone-treated group did not change significantly.

Another novel observation was that poor sleep contributed to rage attacks and aggressive behavior, which became less frequent during trazodone therapy. Because children with rage had poor sleep and responded to trazodone, we recommend that trazodone be used as a first-line agent for the symptomatic treatment of rage in OMS. Of course, treatment of the primary immune defect should always be the preferred therapy, ${ }^{15}$ and when rage does not respond to trazodone, the possibility of an exacerbation of the underlying immunologic abnormality should be considered. Although there have been no previous studies of trazodone for rage, some older children with disruptive behavioral disturbances have responded to trazodone.

Where rage falls within the classification of emotional outbursts in children is not straightforward. Temper tantrums are common between age 18 months ( $87 \%$ of children) and 4 years $(59 \%),{ }^{21}$ the same age range of OMS onset. ${ }^{1}$ The spectrum of behaviors encompassed by tantrums is broad, overlapping in severe cases with what we are calling rage, but tantrums usually are not so extreme, and $75 \%$ last less than 5 minutes. ${ }^{21}$ Rage has been defined as "an unpredictable and primitive display of violence that is out of proportion to the provoking incident and often threatens serious self-injury or harm to others." 22 The medical literature contains overlapping terms to describe severe emotional outbursts, including explosive rage, episodic-dyscontrol syndrome, and intermittent explosive disorder (a DSM-IV classification). We find that "rage" is a simple descriptive term that parents can relate to.

Many parents ask whether steroids or ACTH are responsible for the sleep disturbance of OMS. Our data suggest that these agents can contribute to it. ACTH does activate rapid eye movement (REM)-related phasic inhibition during REM sleep. ${ }^{12}$ However, irritability and sleeplessness are characteristic features of the OMS prodrome, well before any treatment is initiated. In addition, some parents report that their child's sleep is much improved on steroid or ACTH 
treatment, or that withdrawal from steroid or $\mathrm{ACTH}$ therapy is associated with increased sleep problems.

The exact mechanism of trazodone's soporific effect in OMS is unclear because of its multiple potential modes of action, some of which are opposing. ${ }^{4}$ The greatest affinities are for 5-HT receptors, possessing not only agonist-like actions by virtue of inhibiting 5 -HT reuptake, but also antagonist properties at $5-\mathrm{HT}_{2 \mathrm{~A} / 2 \mathrm{C}}$ receptors at higher doses. The trazodone metabolite $\mathrm{m}-\mathrm{CPP}$ is an agonist at $5-\mathrm{HT}_{\mathrm{IA}}$ and $5-\mathrm{HT}_{\mathrm{IC}}$ receptors and a weak antagonist at $5-\mathrm{HT}_{2}$ receptors. However, the sleep disruption and behavioral activation caused by administration of $\mathrm{m}-\mathrm{CPP}$ alone suggest that the sedative-hypnotic effect of the parent compound is unrelated to $\mathrm{m}$-CPP in humans. ${ }^{23}$ Trazodone also has some nonserotonergic properties that may be at play. ${ }^{24}$

The complexity of sleep physiology and pharmacology implicates multiple neurotransmitters (ie, serotonin, noradrenaline, dopamine, $\gamma$-aminobutyric acid, adenosine, acetylcholine $)^{4,25}$ and brain regions (ie, dorsal raphe nuclei, locus ceruleus, dorsal pontine tegmentum, hypothalamus, thalamus, preoptic/basal forebrain, and superchiasmatic nucleus). ${ }^{26} \mathrm{Be}-$ cause opsoclonus and myoclonus appear to be brainstemmediated in OMS, ${ }^{27}$ the 3 major projection pathways (serotonergic, noradrenergic, and cholinergic) emanating from the brainstem and involved in sleep physiology may be most relevant. However, primitive emotions, such as rage, are increased in certain childhood disorders of the cerebellum, ${ }^{28}$ a site involved in OMS. ${ }^{27}$

Trazodone therapy significantly reduced snoring. Loss of upper airway muscle tone contributes to obstructive sleep apnea/hypopnea, and a 5-HT deficiency state has been suggested. ${ }^{29}$ The involved muscles, innervated by the hypoglossal nerve, are under serotonergic control, and $5-\mathrm{HT}_{2}$ receptor antagonists (including trazodone) can reduce sleep apnea/hypopnea. Although sleep apnea may precipitate daytime inattention, learning difficulties, and possibly hyperactivity, emotional symptoms, and bad conduct, ${ }^{30}$ it seems unlikely that it is a major contributor to the problems seen in our patients, given its relatively low frequency and lack of relation to reduced sleep. Moreover, adenotonsillar enlargement, the most common cause of childhood sleep apnea, ${ }^{31}$ would not be helped by trazodone therapy.

The therapeutic advantage of trazodone over antidepressant agents for sleep disturbance is that trazodone does not suppress REM sleep and increases deep sleep, ${ }^{32}$ which is thought to be important to restorative sleep. This highly lipophilic heterocyclic compound, exhibiting linear kinetics, is relatively safe in overdosage, ${ }^{4}$ which is an important safety issue for young children. It produces the well-known sleep alterations of classical sedative amitriptyline-type antidepressants with fewer side effects. ${ }^{32}$ Children old enough to discern and communicate did not complain of dry mouth or dizziness. Priapism, a rare but serious potential side effect, was not an issue.

Based on how well trazodone is tolerated, we suggest using higher doses as needed in children with more severe rage who have no predisposing risk factors. The dose-equivalent high-dose range used in adults is about 5 to $8 \mathrm{mg} / \mathrm{kg} / \mathrm{day}$. Trazodone doses used in pediatric studies have ranged from 1 to $6 \mathrm{mg} / \mathrm{kg} /$ day. ${ }^{6,7}$ Although the relative risks are low, we would not recommend using trazodone in children with OMS who have active seizure activity ${ }^{33}$ or ACTH- or steroidinduced cardiac problems. ${ }^{4}$

\section{REFERENCES}

1. Tate ED, Allison TJ, Pranzatelli MR, Verhulst SJ. Neuroepidemiologic trends in 105 U.S. cases of pediatric opsoclonus-myoclonus. J Pediatric Oncol Nurs 2005;22:8-19.

2. Boyle J, Cropley M. Children's sleep: problems and solutions. J Fam Health Care 2004;14:61-3.

3. Tate ED, Pranzatelli MR, Huang Y-Y, Kaplan R. An innovative approach to the problem of sedating children with opsoclonus-myoclonus syndrome: effect on myoclonus and CSF monoamine metabolites. Ann Neurol 1994;36:543-4.

4. Haria M, Fitton A, McTavish D. Trazodone: a review of its pharmacology, therapeutic use in depression and therapeutic potential in other disorders. Drugs Aging 1994;4:331-55.

5. Mashiko H, Niwa S, Kumashiro H, Kaneko Y, Suzuki S, Numata Y, et al. Effect of trazodone in a single dose before bedtime for sleep disorders accompanied by a depressive state: a dose-finding study with no concomitant use of hypnotic agent. Psychiatry Clin Neurosci 1999;53:193-4.

6. Battistella PA, Ruffilli R, Cernetti R, Pettenazzo A, Baldin L, Bertoli S, et al. A placebo-controlled crossover trial using trazodone in pediatric migraine. Headache 1993;33:36-9.

7. Zubieta JK, Alessi NE. Acute and chronic administration of trazodone in the treatment of distuptive behavior disorders in children. J Clin Psychopharmacol 1992;12:346-51.

8. Levi G, Sogos C. Depressive disorder in pre-adolescence: comorbidity or different clinical subtypes? (A pharmacological contribution). Isr J Psychiatry Relat Sci 1997;34:187-94.

9. Balon R. Sleep terror disorder and insomnia treated with trazodone: a case report. Ann Clin Psychiatry 1994;6:161-3.

10. Pranzatelli MR, Huang Y-Y, Tate E, Stanley M, Noetzel MJ, Gospe $\mathrm{SM}$, et al. Cerebrospinal fluid 5-hydroxyindoleacetic acid and homovanillic acid in the pediatric opsoclonus-myoclonus syndrome. Ann Neurol 1995;37: 189-97.

11. Kruesi MJP, Rapoport JL, Hamburger S, Hibbs E, Potter WZ. Cerebrospinal fluid monoamine metabolites, aggression and impulsivity in disruptive behavior disorders of children and adolescents. Arch Gen Psychiatry 1990;47:419-26.

12. Kohyama J, Shimohira M, Tanuma N, Hasegawa T, Iwakawa $Y$. ACTH activates rapid eye movement-related phasic inhibition during REM sleep in patients with infantile spasms. Acta Neurol Scand 2000;100: 145-52.

13. Pranzatelli MR, Huang Y-Y, Tate E, Goldstcin DS, Holmes CS, Goldstein EM, et al. Effect of high-dose corticotropin on cerebrospinal fluid monoaminergic neurotransmitters or metabolites in corticotropin-responsive pediatric opsoclonus-myoclonus. Mov Disord 1998;13:522-8.

14. O'Brien LM, Holbrook CR, Mervis CB, Klaus CJ, Bruner JL, Raffield TJ, et al. Sleep and neurobehavioral characteristics of 5- to 7-year-old children with parentally reported symptoms of attention deficit/hyperactivity disorder. Pediatrics 2003;111:554-63.

15. Pranzatelli MR, Travelstead A, Tate ED, Allison TJ, Moticka EJ, Franz $\mathrm{DN}$, et al. B- and T-cell markers in opsoclonus-myoclonus: immunophenotyping of CSF and blood lymphocytes. Neurology 2004;62:1526-32.

16. Stores $G$, Wiggs L. Clinical services for sleep disorders. Arch Dis Child 1998;79:495-7.

17. Bonnet MH, Arand DL. Clinical effects of sleep fragmentation versus sleep deprivation. Sleep Med Rev 2003;7:297-310.

18. Sadeh A, Gruber R, Raviv A. The effects of sleep restriction and extension on school-age children: what a difference an hour makes. Child Dev 2003; 74:444-55. 
19. Saletu-Zyhlarz GM, Abu-Bakr MH, Anderer P, Gruber G, Mandl M, Strobl R, et al. Insomnia in depression: differences in objective and subjective sleep and awakening quality to normal controls and acute effect of trazodone. Prog Neuropsychopharmacol Biol Psychiatry 2002;26:249-60.

20. Papini M, Pasquinelli A, Filippini A. Steroid-dependent form of Kinsbourne syndrome: successful treatment with trazodone. Ital J Neurol Sci 1992;13:369-72.

21. Potegal M, Kosorok MR, Davidson RJ. Temper tantrums in young children, 2: tantrum duration and temporal organization. J Dev Behav Pediatr 2003;24:148-54.

22. Mandoki MW, Sumner GS, Matthews-Ferrari K. Evaluation and treatment of rage in children and adolescents. Child Psychiatry Hum Dev 1992;22:227-35.

23. Lawlor BA, Newhouse PA, Balkin TJ, Molchan SE, Mellow AM, Murphy DL, et al. A preliminary study of the effects of nighttime administration of the serotonin agonist, $\mathrm{m}-\mathrm{CPP}$, on sleep architecture and behavior in healthy volunteers. Biol Psychiatry 1991;29:281-6.

24. Ware JC, Pittard JT. Increased deep sleep after trazodone use: a doubleblind placebo-controlled study in healthy young adults. J Clin Psychiatry 1990;51(suppl):18-22.

25. Ursin R. Serotonin and sleep. Sleep Med Rev 2002;6:55-69.
26. Kayama Y, Koyama Y. Control of sleep and wakefulness by brainstem monoaminergic and cholinergic neurons. Acta Neurochir Suppl 2003;87:3-6. 27. Pranzatelli MR. The neurobiology of opsoclonus-myoclonus syndrome. Clin Neuropharmacol 1992;15:186-228.

28. Riva D, Giorgi C. The cerebellum contributes to higher functions during development: evidence from a series of children surgically treated for posterior fossa tumours. Brain 2000;123:1051-61.

29. Veasey SC. Serotonin agonists and antagonists in obstructive sleep apnea: therapeutic potential. Am J Respir Med 2003;2:21-9.

30. Urschitz MS, Eitner S, Guenther A, Eggebrecht E, Wolff J, UrschitzDuprat PM, et al. Habitual snoring, intermittent hypoxia, and impaired behavior in primary school children. Pediatrics 2004;114:1041-8.

31. Hoban TF. Sleep and its disorders in children. Semin Neurol 2004;24: $327-40$.

32. Saletu-Zyhlarz GM, Abu-Bakr MH, Anderer P, Semler B, Decker K, Parapatics $S$, et al. Insomnia related to dysthymia: polysomnographic and psychometric comparison with normal controls and acute therapeutic trials with trazodone. Neuropsychobiology 2001;44:139-49.

33. Pisani F, Spina E, Oteri G. Antidepressant drugs and seizure susceptibility: from in vitro data to clinical practice. Epilepsia 1999;40(suppl 10):S48-56. 